\title{
FORMULATION AND CHARACTERIZATION OF PERIODONTAL FILMS CONTAINING AZITHROMYCIN AND SERRATIOPEPTIDASE
}

\author{
SONIYA RANI*, NARDEV SINGH \\ Department of Pharmaceutics, Uttaranchal Institute of Pharmaceutical Sciences, Uttaranchal University, Dehradun, Uttarakhand, India. \\ Email: soniyarani487@gmail.com
}

Received: 10 October 2017, Revised and Accepted: 25 January 2018

\section{ABSTRACT}

Objective: The objective of the present work was to formulate and evaluate periodontal film, which could be capable of delivering therapeutic concentration of azithromycin and serratiopeptidase for a prolonged period of time and could be easily placed into the periodontal pocket.

Methods: The films were prepared by solvent casting method using combinations of ethyl cellulose, hydroxypropyl methylcellulose K4M, hydroxypropyl methylcellulose $50 \mathrm{cps}$, eudragit L-100, and Chitosan in different ratios using dibutyl phthalate as plasticizer. The periodontal films were evaluated for weight variation, thickness, percentage moisture absorption, percentage moisture loss, folding endurance, percentage swelling index, percentage elongation, and in vitro percentage cumulative drug-enzyme release profile.

Results: Formulation F12 was found to be a good periodontal film. Hence, it was considered as an optimized formulation. In vitro drug-enzyme release rate studies using keshary-chien diffusion cell showed maximum drug release in F12 formulation (95.92\% for azithromycin and $94.20 \%$ for serratiopeptidase at the end of $24 \mathrm{~h}$ ) compared to other formulations.

Conclusion: The optimized formulation F12 showed the best drug-enzyme release profile among the others for the preparation of periodontal film. There is a scope for the further study and development of the azithromycin and serratiopeptidase periodontal films.

Keywords: Periodontal films, Azithromycin and serratiopeptidase, Solvent casting method, keshary-chien diffusion cell.

(C) 2018 The Authors. Published by Innovare Academic Sciences Pvt Ltd. This is an open access article under the CC BY license (http://creativecommons. org/licenses/by/4. 0/) DOI: http://dx.doi.org/10.22159/ajpcr.2018.v11i5.23032

\section{INTRODUCTION}

The oral cavity is an attractive site for drug delivery due to ease of administration and avoidance of possible drug degradation in the gastrointestinal tract and first-pass metabolism. The oral cavity provides a diverse environment for colonization by a wide variety of microorganisms [1]. Periodontal disease is a general term encompassing several pathological conditions such as gingivitis and periodontitis. Periodontitis is a local infection with primary bacterial etiology in the gingival crevices, which affects the structural organs surrounding the teeth such as periodontal ligament, connective tissue, and bone. The warm and moist pocket environment fasters the growth of Gramnegative, anaerobic bacteria that proliferate in the subgingival space. The aim of dental health care is to control the population of microorganisms. Slowing or arresting of the oro-dental infections can be achieved by controlling bacterial plaque [2]. Gingival and periodontal disease has affected the humankind for decades and in now looked on as a principle health problem. About 35\% of adults are affected by periodontitis, of these $13 \%$ adults over 30 years of age have a moderate or severe form of periodontitis and $22 \%$ have a mild form of the disease [3]. Periodontitis is a complex multifactorial disease mainly caused due to Gram-negative microbes and host response to their colonization leading to the destruction of periodontal apparatus. Henceforth, periodontal pocket acts as a source of continuous localized infection which acts as a niche of various potential periodontal pathogens including Actinobacillus actinomycetemcomitans, Porphyromonas gingivalis, Prevotella intermedia, Bacteroides forsythus, Peptostreptococcus micros, Campylobacter rectus, Eikenella corrodens, Fusobacterium nucleatum, Eubacterium spp., Treponema denticola, Selenomonas spp., betahemolytic streptococci, a variety of enteric rods, and Pseudomonas, enterococci, Staphylococci, and possibly yeasts.[4] Azithromycin is a first and most important member of new class of antibiotics known as azalides, used for aerobes and anaerobes found in periodontal pocket.
Azithromycin is commonly used for a wide variety of mild-to-moderate bacterial infections caused by susceptible strains of the designated microorganisms in the specific conditions: Haemophilus influenzae, Moraxella catarrhalis, Streptococcus pneumoniae, Chlamydophila pneumoniae, Mycoplasma pneumoniae, Streptococcus pyogenes, Staphylococcus aureus, Staphylococcus Agal, etc [5]. Serratiopeptidase is an enzyme produced by entering bacterium Serratia sp. E-15, has the potential of developing a therapeutically efficacious system for treatment of periodontal inflammatory anaerobic infections, is a non-steroidal anti-inflammatory drug reduces swelling, and offers a powerful treatment for pain and inflammation. Studies have shown that this enzyme can actually team up with antibiotics and deliver increased concentrations of antibiotics to the site of the infection [6]. To overcome the disadvantages of systemic chemotherapy with antibiotics, recent technical advancements have led to the development of new drug delivery systems that provide controlled therapeutic activity by targeting the delivery of a drug to a particular site. If a particular drug is targeted to a desired site, it minimizes the distribution of the drug to other body organs. Controlled drug delivery systems offer numerous advantages compared with conventional dosage forms [7].

\section{METHODS}

\section{Materials}

Azithromycin and serratiopeptidase used in the formulation and development study were provided by the college. The laboratory reagents and chemicals used in the formulation and development study were supplied by the manufacturer in the college.

\section{Methods}

Periodontal films were prepared by solvent casting technique. The formulations were designed as shown in the Table 1. Glass molds were used for casting the films. Ethylcellulose, hydroxypropyl 
Table 1: It shows formulae used for the development of periodontal films

\begin{tabular}{|c|c|c|c|c|c|c|c|c|c|c|c|c|c|c|c|}
\hline \multirow[t]{2}{*}{ Ingredients } & \multicolumn{15}{|c|}{ Film code } \\
\hline & F1 & F2 & F3 & F4 & F5 & F6 & F7 & F8 & F9 & F10 & F11 & F12 & F13 & F14 & F15 \\
\hline Azithromycin (mg) & 340 & 340 & 340 & 340 & 340 & 340 & 340 & 340 & 340 & 340 & 340 & 340 & 340 & 340 & 340 \\
\hline Serratiopeptidase (mg) & 09 & 09 & 09 & 09 & 09 & 09 & 09 & 09 & 09 & 09 & 09 & 09 & 09 & 09 & 09 \\
\hline Ethyl cellulose (mg) & 1200 & 1150 & 1100 & 1000 & 900 & 1100 & 1000 & 900 & & 450 & 900 & 900 & 450 & 450 & _ \\
\hline HPMC K4M (mg) & 150 & 200 & 250 & 350 & 450 & & & & 450 & _ & _ & _ & _ & _ & -7 \\
\hline HPMC 50cps (mg) & - & - & 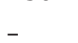 & - & - & 250 & 350 & $\overline{4} 50$ & & - & - & - & - & - & $\overline{4} 50$ \\
\hline EudragitL100 (mg) & - & - & - & - & - & _- & _- & _- & 900 & 900 & 450 & 450 & 450 & 450 & 450 \\
\hline Chitosan (mg) & & & & & & & & & 450 & 450 & 900 & 450 & 900 & 450 & 450 \\
\hline Chloroform (ml) & 10 & 10 & 10 & 10 & 10 & 10 & 10 & 10 & 15 & 15 & 15 & 15 & 15 & 15 & 15 \\
\hline Ethanol (ml) & 10 & 10 & 10 & 10 & 10 & 10 & 10 & 10 & 15 & 15 & 15 & 15 & 15 & 15 & 15 \\
\hline DBP (ml) & 0.2 & 0.2 & 0.2 & 0.2 & 0.2 & 0.2 & 0.2 & 0.2 & 0.3 & 0.3 & 0.3 & 0.3 & 0.3 & 0.3 & 0.3 \\
\hline
\end{tabular}

HPMC: Hydroxypropyl methylcellulose, DBP: Diastolic blood pressure

methylcellulose, eudragit L100, and chitosan were used in different ratios [8]. They were dissolved in chloroform and ethanol mixture with dibutyl phthalate as a plasticizer in a beaker using a magnetic stirrer to get different concentrations of polymeric solutions [9]. Required quantity of azithromycin and serratiopeptidase was taken in spatula and dissolved in a sufficient amount of water. Mercury was poured carefully in the form of the layer into the labeled clean glass molds wrapped in an aluminum foil. After complete mixing, the solution was poured into these molds, placed on a horizontal plane. The solvent was allowed to evaporate slowly by inverting a glass funnel plugged with cotton in the stem at room temperature for $24 \mathrm{~h}$ [10]. The prepared films were packed immediately in individual airtight aluminum seal packs and stored at $25^{\circ} \mathrm{C}$ until used [11].

\section{Characterization of films}

Formulated periodontal films were subjected to the preliminary evaluation tests. Films with any imperfections, entrapped air, or differing in thickness, weight, or content uniformity were excluded from further studies. Physicochemical properties such as thickness, weight uniformity, and percentage moisture loss, folding endurance, surface $\mathrm{pH}$, swelling index, and drug content uniformity of the prepared periodontal films were determined.

\section{Thickness uniformity}

The thickness of each periodontal film was measured using the screw gauge at different 6 positions of the film, and the average was calculated.

\section{Estimation of percentage moisture loss}

6 films of different concentrations of size $(7 \times 4 \mathrm{~mm})$ were weighed accurately, and then, they were kept in desiccators for 3 consecutive days and then reweighed. The percentage moisture loss was calculated by the formula [12].

Moisture loss $=($ initial weight - final weight/initial weight $) \times 100$

\section{Uniformity of weight}

Periodontal film pieces (size of $7 \times 4 \mathrm{~mm}$ ) were taken from different areas of film. The weight variation of each film was calculated [13]

\section{In vitro drug release studies}

Since the $\mathrm{pH}$ of gingival fluid lies between 6.5 and 6.8, phosphate buffer $\mathrm{pH} 6.6$ was used as the simulated gingival fluid. The in vitro drug release was performed using a keshary-Chien (K-C) diffusion cell. Phosphate buffer $\mathrm{pH} 6.6$ was used as a receptor solution as a dissolution medium. The volume of diffusion cell was $10 \mathrm{ml}$. The prepared periodontal film $(7 \times 4 \mathrm{~mm})$ was firmly pressed onto the center of the semipermeable membrane, and then, the membrane was mounted in the donor compartment. The donor compartment was then placed in a position such that the surface of membrane just touches the receptor fluid surface. The whole assembly was fixed on a hot plate magnetic stirrer, and the solution in the receptor compartment was continuously stirred at $100 \mathrm{rpm}$ using magnetic beads and the temperature was maintained at $37 \pm 1^{\circ} \mathrm{C}$. The diffusion was carried out for $24 \mathrm{~h}$ and $1 \mathrm{ml}$ of the receptor fluid was withdrawn at predetermined time interval and replaced immediately with the same volume of fresh dissolution media to maintain sink conditions. The samples were analyzed for drug release at $216 \mathrm{~nm}$ and $226 \mathrm{~nm}$ using ultraviolet (UV) visible spectrophotometer after suitable dilution with diffusion media [14].

\section{Drug content uniformity}

The prepared film formulations were analyzed for drug content by taking film (size of $7 \times 4 \mathrm{~mm}$ ) from each batch and individually dissolved in $5 \mathrm{ml}$ of $\mathrm{pH} 6.6$ phosphate buffer in a beaker. The dispersion was kept in the dark place for overnight. The dispersion was filtered. $0.1 \mathrm{ml}$ of the filtered solution was diluted to $10 \mathrm{ml}$ with $\mathrm{pH} 6.6$ phosphate buffer in a $10 \mathrm{ml}$ volumetric flask. Drug concentrations were determined by taking three readings, using a UV visible spectrophotometer at 216 NM and 226nm [15]

\section{Tensile strength}

The tensile strength was determined by the apparatus designed. A small film $(7 \times 4 \mathrm{~mm})$ was cut on a glass plate with a sharp blade. The instrument was designed such that it had a horizontal wooden platform with fixed scale and attachments for two clips that hold periodontal film under test. Of the two clips, one was fixed and another was movable. Weights were hanged to one end of the pulley and the other end of the pulley was attached to movable clip. The wooden platform was such fitted that it would not dislocate while the test is running. To determine elongation and tensile strength, the film was pulled by means of a pulley system. Weights were gradually added to the pan to increase the pulling force till the film was broken. Percentage elongation and tensile strength were calculated using the following formulae $[16,17]$.

\section{Swelling index}

Swelling index of the drug-loaded films was determined by placing the film (area $7 \times 4 \mathrm{~mm}$ ) in the Petridis containing about $10.0 \mathrm{ml}$ of phosphate buffer $\mathrm{pH}$ 6.6, and before placing the film in the Petridis, its initial weight was calculated and increase in weight due to swelling was determined by weighing the film at predetermined time interval [18].

\section{Folding endurance}

The folding endurance value for all periodontal films was $>200$; it indicates that all formulations had ideal periodontal film properties [19].

\section{Surface $\mathbf{p H}$}

Surface $\mathrm{pH}$ of all the formulations was determined. All the formulations were found to have a pH between 6 and 7. This reveals that the prepared periodontal films would not alter the $\mathrm{pH}$ of the gingival fluid in the periodontal pocket and therefore may not cause any irritation $[20,21]$

\section{RESULTS}

To confirm the identity, purity, and stability of drugs for formulation and to establish a drug profile, preformulation studies were undertaken. Identification of azithromycin and serratiopeptidase was performed by UV visible spectroscopic method. The maximum absorption of 
azithromycin and serratiopeptidase was found at $216 \mathrm{~nm}$ and $229 \mathrm{~nm}$, respectively. The standard curves of azithromycin and serratiopeptidase were prepared in $\mathrm{pH} 6.6$ phosphate buffer.

\section{Thickness of the films}

The thickness of each film was measured at 6 different points and the average thickness with a standard deviation was calculated. The data on periodontal films thickness indicated that there was no much difference in the thickness within the formulations. The order of the thickness of the periodontal films is $\mathrm{F} 12<\mathrm{F} 11<\mathrm{F} 9<\mathrm{F} 10<\mathrm{F} 13<\mathrm{F} 15<\mathrm{F} 14<\mathrm{F} 8<\mathrm{F} 7<\mathrm{F} 2<$ $\mathrm{F} 4<\mathrm{F} 5<\mathrm{F} 3<\mathrm{F} 6<\mathrm{F} 1$.

\section{Tensile strength}

The order of tensile strength of the periodontal films is $\mathrm{F} 12<\mathrm{F} 14<\mathrm{F} 13<$ $\mathrm{F} 15<\mathrm{F} 11<\mathrm{F} 10<\mathrm{F} 9<\mathrm{F} 8<\mathrm{F} 7<\mathrm{F} 6<\mathrm{F} 5<\mathrm{F} 4<\mathrm{F} 3<\mathrm{F} 2<\mathrm{F} 1$. The tensile strength is shown in Table 2 .

\section{Drug content uniformity}

The percentage drug content in various formulations ranged from $84.38 \%$ to $96.20 \%$ of azithromycin and $84.73 \%$ to $94.50 \%$ of serratiopeptidase is given in Table 3. It was observed from the

Table 2: Tensile strength of loaded and unloaded periodontal films

\begin{tabular}{lll}
\hline Film code & \multicolumn{2}{l}{ Tensile strength $\left(\mathrm{Kg} / \mathbf{m m}^{2}\right)$} \\
\cline { 2 - 3 } Unloaded films & Loaded films \\
\hline F1 & $2.366 \pm 0.162$ & $2.706 \pm 0.032$ \\
F2 & $2.254 \pm 0.015$ & $2.420 \pm 0.04$ \\
F3 & $2.204 \pm 0.098$ & $2.381 \pm 0.077$ \\
F4 & $2.105 \pm 0.121$ & $2.211 \pm 0.042$ \\
F5 & $1.724 \pm 0.026$ & $2.154 \pm 0.044$ \\
F6 & $1.24 \pm 0.0184$ & $1.998 \pm 0.056$ \\
F7 & $1.50 \pm 0.062$ & $1.93 \pm 0.043$ \\
F8 & $1.39 \pm 0.021$ & $1.92 \pm 0.051$ \\
F9 & $1.54 \pm 0.023$ & $1.87 \pm 0.034$ \\
F10 & $1.67 \pm 0.041$ & $1.81 \pm 0.028$ \\
F11 & $1.45 \pm 0.050$ & $1.56 \pm 0.032$ \\
F12 & $1.01 \pm 0.31$ & $1.15 \pm 0.0201$ \\
F13 & $1.11 \pm 0.025$ & $1.31 \pm 0.035$ \\
F14 & $1.05 \pm 0.056$ & $1.27 \pm 0.024$ \\
F15 & $1.09 \pm 0.032$ & $1.44 \pm 0.041$ \\
\hline
\end{tabular}

*Each reading is at least three determinations drug content data that there was no significant difference in the uniformity of the drug content. However, when compared with the theoretical drug content, the estimated drug content was slightly less in both drugs. It may be due to the drug loss during fabrication of the periodontal films.

\section{Weight uniformity test}

Drug loaded films $(7 \times 4 \mathrm{~mm})$ were tested for uniformity of weight, and the results of weight uniformity are given in Table 3 . Lesser standard deviation values indicated that the films were uniform in weight. Weight variation ranged from $10.40 \pm 0.11$ to $11.15 \pm 0.116 \mathrm{mg}$. The order of the weight of periodontal films is F14<F15<F12<F13<F11<F10<F9<F6<F7 $<\mathrm{F} 8<\mathrm{F} 5<\mathrm{F} 4<\mathrm{F} 3<\mathrm{F} 2<\mathrm{F} 1$

\section{Percentage moisture absorption}

Percentage moisture absorption was found to be ranged from $8.10 \pm 0.04$ to $15.20 \pm 0.02$. The percentage moisture absorption is shown in Table 3 .

\section{Swelling index}

Swelling index of all films was calculated and it was in the range of 10.51 $\pm 0.04-28.24 \pm 0.04$. A formulation containing ethyl cellulose and hydroxypropyl methylcellulose K4M shows maximum swelling property than the other films. As the concentration of polymer increased, swelling index also increased. Swelling is very essential before the drug is released from the dosage form. The swelling index is shown in Table 3.

\section{Percentage elongation}

Percentage elongation was found to be ranged from $6.47 \pm 0.004$ to $14.5 \pm 0.04$. The swelling index was reported in Table 3 .

\section{Percentage moisture loss}

The percentage moisture loss was found to be in the range of $7.88 \pm 0.05-15.02 \pm 0.05$. Moisture loss studies were conducted on all the formulations and reported in Table 3.

\section{Surface pH}

Surface $\mathrm{pH}$ of all the formulations was determined as described in the methodology chapter. All the formulations were found to have a $\mathrm{pH}$ between 6 and 7. This reveals that the prepared films would not alter the $\mathrm{pH}$ of the gingival fluid in the periodontal pocket and therefore may not cause any irritation.

Table 3: Various physicochemical properties of periodontal films

\begin{tabular}{|c|c|c|c|c|c|c|c|c|}
\hline $\begin{array}{l}\text { Film code } \\
\text { parameters }\end{array}$ & F1 & F2 & F3 & F4 & F5 & F6 & F7 & F8 \\
\hline $\begin{array}{l}\text { Weight } \\
\text { Variation (mg)* }\end{array}$ & $11.15 \pm 0.116$ & $11.12 \pm 0.046$ & $11.08 \pm 0.276$ & $11.05 \pm 0.38$ & $11.01 \pm 0.21$ & $10.92 \pm 0.24$ & $10.95 \pm 0.10$ & $10.96 \pm 0.128$ \\
\hline Thickness (mm)* & $0.44 \pm 0.004$ & $0.40 \pm 0.009$ & $0.42 \pm 0.0016$ & $0.041 \pm 0.0070$ & $0.41 \pm 0.0014$ & $0.43 \pm 0.012$ & $0.39 \pm 0.002$ & $0.37 \pm 0.0291$ \\
\hline $\begin{array}{l}\% \text { Moisture } \\
\text { Absorption* }\end{array}$ & $8.10 \pm 0.04$ & $8.94 \pm 0.03$ & $9.63 \pm 0.01$ & $8.16 \pm 0.04$ & $11.35 \pm 0.02$ & $12.92 \pm 0.04$ & $13.01 \pm 0.01$ & $15.20 \pm 0.024$ \\
\hline \% Moisture Loss* & $7.88 \pm 0.05$ & $9.24 \pm 0.037$ & $10.99 \pm 0.06$ & $8.96 \pm 0.03$ & $11.31 \pm 0.042$ & $19.95 \pm 0.06$ & $20.51 \pm 0.05$ & $28.24 \pm 0.043$ \\
\hline \% Swelling index* & $18.32 \pm 0.06$ & $19.18 \pm 0.04$ & $20.26 \pm 0.05$ & $20.51 \pm 0.04$ & $22.52 \pm 0.06$ & $16.57 \pm 0.03$ & $16.13 \pm 0.02$ & $19.57 \pm 0.052$ \\
\hline$\%$ Elongation* & $6.47 \pm 0.04$ & $8.71 \pm 0.01$ & $10.56 \pm 0.02$ & $11.71 \pm 0.04$ & $12.85 \pm 0.01$ & $12.63 \pm 0.06$ & $12.90 \pm 0.05$ & $14.90 \pm 0.021$ \\
\hline $\begin{array}{l}\text { Film code } \\
\text { parameters }\end{array}$ & F9 & F10 & F11 & F12 & F13 & F14 & F15 & \\
\hline $\begin{array}{l}\text { Weight } \\
\text { Variation (mg)* }\end{array}$ & $10.90 \pm 0.31$ & $10.87 \pm 0.21$ & $10.85 \pm 0.0211$ & $10.73 \pm 0.240$ & $10.84 \pm 0.10$ & $10.40 \pm 0.10$ & $10.61 \pm 0.20$ & \\
\hline Thickness $(\mathrm{mm})^{*}$ & $0.30 \pm 0.001$ & $0.31 \pm 0.002$ & $0.29 \pm 0.008$ & $0.25 \pm 0.002$ & $0.31 \pm 0.008$ & $0.35 \pm 0.029$ & $0.32 \pm 0.005$ & \\
\hline \% Moisture Loss* & $23.05 \pm 0.02$ & $10.51 \pm 0.04$ & $11.05 \pm 0.02$ & $20.24 \pm 0.04$ & $15.52 \pm 0.06$ & $14.56 \pm 0.01$ & $11.21 \pm 0.05$ & \\
\hline Folding endurance & 249 & 251 & 270 & 190 & 235 & 221 & 205 & \\
\hline \% Swelling index* & $23.22 \pm 0.01$ & $29.04 \pm 0.03$ & $29.22 \pm 0.05$ & $31.04 \pm 0.01$ & $28.75 \pm 0.04$ & $23.54 \pm 0.03$ & $22.79 \pm 0.04$ & \\
\hline \% Elongation* & $13.99 \pm 0.06$ & $14.2 \pm 0.01$ & $14.5 \pm 0.04$ & $15.02 \pm 0.05$ & $13.60 \pm 0.05$ & $13.41 \pm 0.03$ & $13.28 \pm 0.04$ & \\
\hline
\end{tabular}


Folding endurance

The folding endurance value for all films was $>200$; it indicates that all formulations had ideal periodontal film properties.

In vitro percentage cumulative drug-enzyme release profile formulation $\mathrm{F} 12$

The formulation F12 was found to be a good periodontal film. Hence, it was considered as an optimized formulation. In vitro drug-enzyme release rate studies using $\mathrm{K}-\mathrm{C}$ diffusion cell showed maximum drug release in F12 formulation (95.92\% for azithromycin and $94.20 \%$ for serratiopeptidase at the end of $24 \mathrm{~h}$ ) compared to other formulations

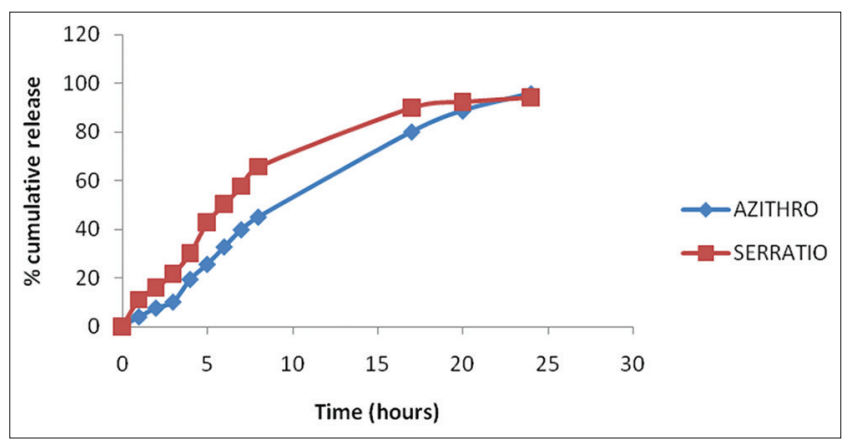

Fig. 1: Percentage cumulative drug-enzyme release profile formulation F12

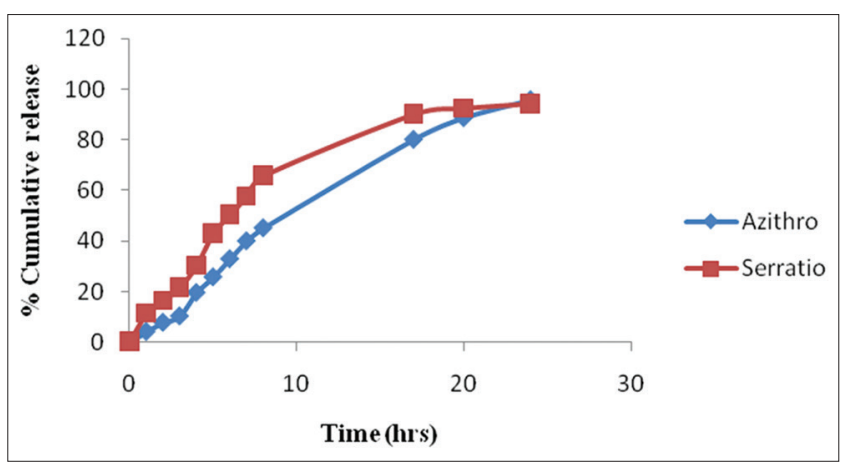

Fig. 2: Zero-order kinetic of F12

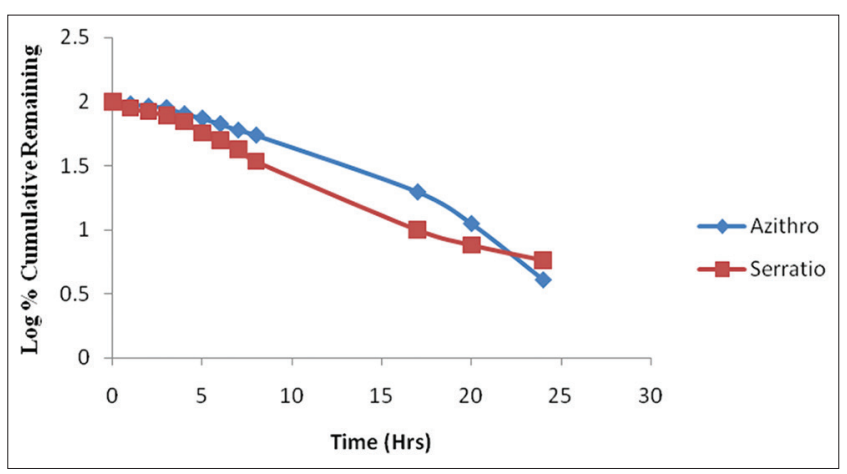

Fig. 3: First-order kinetic of F12 as shown in Fig. 1 and kinetic data of in vitro release of periodontal film formulation F12 as shown in Table 4 and Figs. 1-5.

\section{DISCUSSION}

The azithromycin and serratiopeptidase formulated had a better release profile. This is the first time that an attempt was made to formulate a delivery system containing drug and enzyme. Fifteen formulations were formulated by a solvent casting method using combinations of EC, hydroxypropyl methylcellulose (HPMC) K4M, HPMC $50 \mathrm{cps,}$ eudragit L-100, and Chitosan in different ratios using dibutyl phthalate as plasticizer. Both polymer combinations used for fabrication of periodontal films showed good film-forming properties. All fabricated films were thin, elastic, and transparent except for formulation F1-F4 which was light yellowish-brown in appearance. Partition coefficient $(\log P)$ value of azithromycin is 1.47 in an n-butanol and phosphate buffer $\mathrm{pH} 6.6$ systems. It indicates the lipophilic character of azithromycin and may possess high permeability in periodontal pockets. The folding endurance value for ethyl cellulose:eudragit L 100:chitosan films was > 230, HPMC 50 cps:eudragit L 100:Chitosan was > 200, ethyl cellulose:HPMC 50 cps was 170-210, and ethyl cellulose:HPMC K4M films was $>160$. It indicates that all formulations had ideal film properties. The film thickness data indicate that there were no much difference in the thickness within the formulations. Thickness of the films ranged from $0.25 \pm 0.002$ to $0.44 \pm 0.004 \mathrm{~mm}$.

The percentage drug content in various formulations ranged from $84.38 \%$ to $96.20 \%$ for azithromycin and $86.81 \%$ to $94.50 \%$ for serratiopeptidase. In vitro studies of drug-enzyme were carried out in pH 6.6 phosphate buffer, which showed that there was an abrupt release initially and thereafter the release of drug-enzyme was found to be controlled. Overall, formulation F12 was found to be a good periodontal film. Hence, it was considered as an optimized formulation. In vitro drug-enzyme release rate studies using $\mathrm{K}-\mathrm{C}$ diffusion cell showed maximum drug release in F12 formulation (95.92\% for azithromycin and $94.20 \%$ for serratiopeptidase at the end of $24 \mathrm{~h}$ ) compared to other formulations. Formulation F12 containing EC:eudragit:chitosan (2:1:1) exhibited higher tensile strength as compared to other formulations, whereas percentage elongation was observed reverse. The release kinetics indicated zero-order release of azithromycin and first-order release for serratiopeptidase. Higuchi plot for the formulation F12 revealed that the predominant mechanism of drug release is diffusion. However, from Pappas's plot, the "n" value for F12 was found to be around 0.5 and 1 , thus indicating non-Fickian diffusion, which indicates that drug release mechanism involves chain relaxation mechanism.

\section{CONCLUSION}

In the present study, an attempt was made to formulate and evaluate periodontal film, which could be capable of delivering therapeutic concentration of azithromycin and serratiopeptidase for a prolonged period of time and could be easily placed into the periodontal pocket.

The percentage drug content in various formulations ranged from $84.38 \%$ to $96.20 \%$ for azithromycin and $86.81 \%$ to $94.50 \%$ for serratiopeptidase. It was observed from the data that there were no significant differences in the uniformity of the drug content. However, when compared with the theoretical drug content, the estimated drug content was slightly less indicating drug loss during the fabrication of the films.

Table 4: Kinetic data of in vitro release of periodontal films formulation F12

\begin{tabular}{|c|c|c|c|c|c|c|c|c|c|c|}
\hline \multirow{3}{*}{$\begin{array}{l}\text { Film } \\
\text { Code }\end{array}$} & \multirow{2}{*}{\multicolumn{2}{|c|}{ Zero Oder $\left(\mathbf{R}^{2}\right)$}} & \multirow{2}{*}{\multicolumn{2}{|c|}{ First Order $\left(\mathrm{R}^{2}\right)$}} & \multicolumn{2}{|c|}{ Higuchi $\left(\mathrm{R}^{2}\right)$} & \multicolumn{4}{|c|}{ Korsmeyers-Peppas } \\
\hline & & & & & (n) & & $\left(\mathbf{R}^{2}\right)$ & & & \\
\hline & Azithro & Serratio & Azithro & Serratio & Azithro & Serratio & Azithro & Serratio & Azithro & Serratio \\
\hline F12 & 0.975 & 0.879 & 0.963 & 0.991 & 0.946 & 0.957 & 1.004 & 0.729 & 0.975 & 0.953 \\
\hline
\end{tabular}




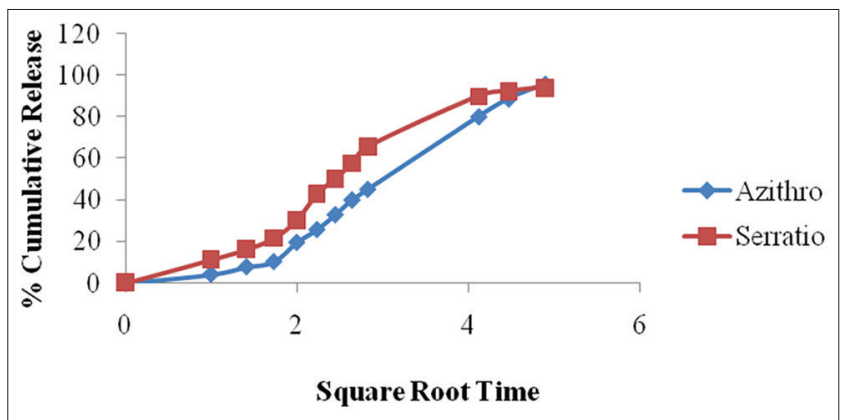

Fig. 4: Higuchi model kinetic of F12

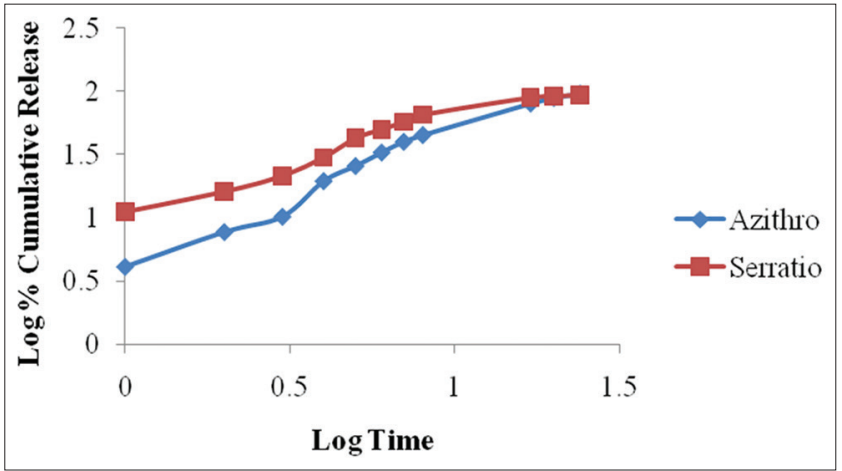

Fig. 5: Korsemeyers-Peppas Model Kinetic of F12

Overall, formulation F12 was found to be a good periodontal film. Hence, it was considered as an optimized formulation. In vitro drug-enzyme release rate studies using $\mathrm{K}$-C diffusion cell showed maximum drug release in F12 formulation (95.92\% for azithromycin and $94.20 \%$ for serratiopeptidase at the end of $24 \mathrm{~h}$ ) compared to other formulations. Formulation F12 containing EC:eudragit:chitosan (2:1:1) exhibited higher tensile strength as compared to other formulations, whereas percentage elongation was observed reverse. Higuchi plot for the formulation F12 revealed that the predominant mechanism of drug release is diffusion. However, from Pappas's plot, the "n" value for F12 was found to be around 0.5 and 1 indicating non-Fickian diffusion, which indicates that drug release mechanism involves chain relaxation mechanism.

\section{CONFLICTS OF INTERESTS}

None

\section{AUTHORS CONTRIBUTION}

Soniya Rani designed the study, developed the methodology, collected the data and performed the analysis of the results.

Nardev singh contributed in writing the manuscript.

\section{REFERENCES}

1. Preeti SK, Mahendra DK. Ciprofloxacin $\mathrm{HCl}$ loaded cubic phase gel for periodontal intrapocket administration. Res J Pharm Biol Chem Sci
2012;3:869-70.

2. Kornman KS. Controlled-release local delivery antimicrobials in periodontics: Prospects for the future. J Periodontol 1993;64:782-91.

3. Dodwad V, Vaish S, Chhokra M, Mahajan A. Magic bullet to treat periodontitis-a targeted approach. J Pharm Biomed Sci 2012;20:1-2.

4. Slots J, Rams TE. Microbiology of periodontal disease. In: Slots J, Taubman MA, editros. Contemporary Oral Microbiology and Immunology. St. Louis: CV Mosby Co.; 1992. p. 425-43.

5. Newman MG, Takei HH, Klokkevold PR, Carranza FA. Clinical Periodontal. $10^{\text {th }}$ ed. Elsevier, St Louis (MO); 2006 . p. 232-5.

6. Vandana G, Umesh L, Neetin D. A quick hplc method for quantification of serratiopeptidase from Serratia marcescens using. J Pharm Res 2016;6:54-60.

7. Vineetha VC, Maria M. Maths development and evaluation of dental films containing an antibacterial agent for the treatment of periodontitis. Int J Pharm Pharm Sci 2014;7:52-9.

8. Magnusson I, Lindhe J, Yoneyamma T, Lilzenberg B. Recolonization of subgingival microbials following scaling in deep pockets. J Clin Periodontal 1984;11:193-207.

9. Esposito E, Cortesi R, Cervellati F, Menegatti E, Nastruzzi C. Biodegradable microparticles for sustained delivery of tetracycline to the periodontal pocket-formulary and drug release studies. J Microencapsul 1997;14:175-87.

10. Rahman S, Ahuja A, Ali J, Khar RK. Site specific delivery systems for the treatment of periodontitis. Indian J Pharm Sci 2003;65:106-12.

11. Yassin GE, Abass HA. Design and evaluation of fast dissolving oro-dispersible films of metoclopramide hydrochloride using 32 multifactorial designs. Int J Pharm Pharm Sci 2016;8:218-22.

12. Nair SC, Anoop KR. Design and in vitro evaluation of controlled release satranidazole subgingival films for periodontitis therapy. Int $\mathbf{J}$ Pharm Sci Rev Res 2014;24:8-14.

13. Manubolu K, Chandana AV, Prakash P. Formulation and in vitro characterizations of amitriptyline buccal films. World J Pharm Pharm Sci 2014;3:1547-55.

14. Mona SA, Semalty KG. Formulation and characterization of mucoadhesive buccal films of glipizide. Indian $\mathrm{J}$ Pharm Sci 2008;704:3-8.

15. Prashant M, Satturwar S, Fulzele V, Avinash K. Dorle evaluation of polymerized rosin for the formulation and development transdermal drug delivery systems. AAPS Pharmscitech 2005;6:48-53.

16. Fulzele SV, Sattuwar PM, Dorle AK. Polymerized rosin: Novel film forming polymer for drug delivery. Int J Pharm 2002;249:175-84.

17. Nakahara T, Nakamura T, Kobayashi E, Inoue M, Shigeno K. Novel approach to regeneration of periodontal tissues based on in situ tissue engineering: Effects of controlled release of basic fibroblast growth factor from a sandwich membrane. Tissue Eng 2003;9:153-62.

18. Renvert S, Lessem J, Dahle NG, Lindahl C, Svensson M. Topical minocycline microspheres versus topical chlorhexidine gel as an adjunct to mechanical debridement of incipient periimplant infections: A randomized clinical trial. J Clin Periodontol 2006;33:362-9

19. Salvi GE, Mombelli A, Mayfield L, Rutar A, Suvan J, Garrett S, et al. Local antimicrobial therapy after initial periodontal treatment. J Clin Periodontol 2002;29:540-50.

20. Minabe M. Application of a local drug delivery system to periodontal therapy. I. Development of collagen preparation with immobilized tetracycline. J Periodontal 1989;60:113-7.

21. Chadha VS, Arora K, Manjunath BC, Kalra S. Local drug delivery in periodontics-current concepts and trends. Int J Adv Res Oral Sci 2012;1:1-9. 